\title{
PENGARUH KEGIATAN EKSTRAKURIKULER OLAHRAGA TERHADAP PERKEMBANGAN LIFE SKILLS SISWA
}

\author{
Budiman', Ruslan Rusmana² \\ 1,2 STKIP Pasundan \\ E-mail: budiimann13@gmail.com¹, ruslan.rusmana24@gmail.com² \\ DOI: https://doi.org/10.36526/kejaora.v6i2.1557
}

\begin{abstract}
ABSTRAK
Penelitian ini bertujuan untuk mengetahui pengaruh kegiatan ekstrakurikuler olahraga terhadap perkembangan life skills siswa. Metode penelitian yang digunakan adalah metode eksperimen dengan desain The Randomized Pretest-Posttest Control Group Design. Populasi penelitian ini adalah seluruh siswa yang mengikuti kegiatan ekstrakurikuler olahraga futsal SMKN 9 Kab. Garut berjumlah 50 orang. Sampel berjumlah 30 orang diambil menggunakan teknik simple random sampling. Sampel terdiri dari dua kelompok yaitu kelompok eksperimen berjumlah 15 orang dan kelompok kontrol berjumlah 15 orang. Instrumen yang digunakan angket life skills yang disusun oleh peneliti. Uji hipotesis penelitian ini dengan menggunakan uji independent samples test, dengan bantuan SPSS versi 25 dengan taraf signifikasi $a=0,05$. Hasil analisis data menunjukkan bahwa terdapat perbedaan pengaruh hasil life skills pada kelompok eksperimen dan kelompok kontrol dengan nilai Sig.(2-tailed) sebesar 0,000 $<0,05$. Dari hasil analisis, dapat disimpulkan bahwa ekstrakurikuler futsal yang diintegrasikan program life skills memberikan pengaruh yang lebih signifikan daripada ekstrakurikuler futsal tanpa integrasi program life skills terhadap peningkatan life skills siswa.
\end{abstract}

Kata Kunci: Life Skills, Integrasi, Ekstakurikuler, Futsal

\section{PENDAHULUAN}

Persaingan Sumber Daya Manusia yang sangat kompetitif pada Era Revolusi Industri 4.0 begitu sangat terasa. Untuk dapat bertahan di tengah persaingan ketat ini, dibutuhkan kualitas SDM Indonesia yang mumpuni. Kecakapan hidup (life skills) SDM yang baik merupakan salah satu bekal yang sangat dibutuhkan pada era saat ini. Rohmanasari et al., (2019) menjelaskan bahwa seseorang dengan usia produktif kerja perlu memiliki life skills agar dapat bersaing dan menjalani tuntutan dan tantangan kehidupan nyata sehari-hari. (Budiman et al., 2020) menambahkan bahwa didalam lingkungan sekolah, siswa perlu dibekali berbagai kecakapan hidup (life skills) sehingga siswa dapat dipersiapkan menjadi manusia masa depan seutuhnya yang berkualitas dan unggul serta siap menghadapi perubahan kehidupan yang semakin cepat dan kompleks. Life skills pada dasarnya merupakan kemampuan seseorang untuk dapat melakukan adaptasi serta memiliki perilaku positif sebagai bekal dalam menghadapi tuntutan dan tantangan kehidupan sehari-hari. Danish et al., (2004) mendefinisikan kecakapan hidup (life skills) sebagai keterampilan yang memungkinkan individu berhasil dalam lingkungan yang berbeda di mana mereka tinggal, seperti sekolah, rumah dan di lingkungan mereka. Menurut Bean et al., (2015), kecakapan hidup secara umum dapat diklasifikasikan sebagai intrapersonal (misalnya, fokus, ketekunan, penetapan tujuan, regulasi emosional) dan interpersonal (misalnya, sportivitas, kejujuran, kerjasama tim, rasa hormat).

Kegiatan olahraga yang disusun secara sengaja dapat mengembangkan keterampilan hidup (Fraser-thomas et al., 2007). Beberapa penelitian seperti yang dilakukan Holt et al., (2015); Jones \& Lavallee, (2009) menunjukkan temuan bahwa siswa merasa telah mengembangkan keterampilan hidup melalui pengalaman 
Jurnal Kejaora: Jurnal Kesehatan Jasmani dan Olah Raga

ISSN: 2541-5042 (Online)

ISSN: 2503-2976 (Print)

Volume 6 Nomor 2, Edisi November 2021

olahraga. Keterlibatan olahraga memiliki potensi untuk membantu siswa mengembangkan emosi serta harga diri yang lebih baik, memperluas jaringan sosial, citra diri yang lebih baik, peningkatan rasa memiliki dan penurunan tingkat depresi dan tekanan emosional (Camiré \& Trudel, 2013; Fredricks \& Eccles, 2006; Harrison \& Narayan, 2006). Melalui penelitian yang telah dilakukan, diketahui bahwa dengan partisipasi olahraga yang diikuti dapat membuat remaja mengembangkan berbagai keterampilan hidup seperti penetapan tujuan, pemecahan masalah dan waktu keterampilan manajemen (Johnston et al., 2012). Remaja yang terlibat aktif dalam olahraga juga telah menunjukkan tingkat keterampilan psikososial yang lebih tinggi seperti perilaku, efikasi diri yang dirasakan, tanggung jawab pribadi, dan tanggung jawab sosial (Carreres-Ponsoda et al., 2012).

Kegiatan ekstrakurikuler olahraga merupakan salah satu hal yang memberikan peranan penting dalam membangun keterampilan serta pengembangan life skills siswa. Fakta bahwa kegiatan ekstrakurikuler olahraga memungkinkan siswa untuk menghabiskan waktu luang mereka secara bermanfaat dan mengarahkan mereka ke kegiatan rekreasi yang berkontribusi terhadap pengembangan individu (Esen, 2010). Ekstrakurikuler olahraga memberikan kontribusi dalam meningkatkan pengalaman sekolah serta meningkatkan keterampilan sosial siswa dalam banyak hal (Durhan, 2021). Kegiatan olahraga ekstrakurikuler mengajarkan ketekunan sambil mendorong penghormatan terhadap aturan, permainan yang adil dan kerja tim (Durhan, 2021). Berbagai penelitian telah menunjukkan adanya pengaruh positif ekstakurikuler olahraga terhadap pengembangan life skills. Meskipun demikian, penelitian-penelitian terkait life skills yang diintegrasikan dalam ekstrakurikuler di Indonesia masih sangat minim diperoleh. Untuk itu diperlukan adanya penelitian terkait yang dilakukan di Indonesia, sebagai upaya penguatan argumen dari penelitian-penelitian sebelumnya.

\section{METODE}

Metode penelitian yang digunakan adalah metode eksperimen dengan desain The Randomized Pretest-Posttest Control Group Design (Fraenkel et al., 2012, p. 272) dapat dilihat pada Tabel 1.

Tabel 1. Desain Penelitian

\begin{tabular}{lllll}
$\begin{array}{l}\text { Treatment } \\
\text { group }\end{array}$ & $\mathrm{R}$ & $\mathrm{O}$ & $\mathrm{X}$ & $\mathrm{O}$ \\
\hline $\begin{array}{l}\text { Control } \\
\text { group }\end{array}$ & $\mathrm{R}$ & $\mathrm{O}$ & $\mathrm{C}$ & $\mathrm{O}$ \\
\hline
\end{tabular}

Keterangan: kelompok perlakuan adalah kelompok ekstrakurikuler olahraga futsal yang diberi perlakuan; kelompok kontrol adalah kelompok ekstrakurikuler olahraga futsal yang tidak diberi perlakuan; $R$ merupakan random (penentuan secara acak menggunkan teknik random sampling); 01 adalah pre-test; 02 adalah post-test; $\mathrm{X}$ merupakan perlakuan, dalam hal ini adalah program integrasi life skills ke dalam latihan olahraga dan C adalah kontrol atau pembanding.

Populasi penelitian ini adalah seluruh siswa yang mengikuti kegiatan ekstrakurikuler olahraga futsal SMKN 9 Garut berjumlah 50 orang. Sampel diambil menggunakan teknik simple random sampling, berjumlah 30 orang yang terdiri dari dua kelompok yaitu, kelas eksperimen berjumlah 15 orang dan kelas kontrol berjumlah 15 orang.

Treatment pada kelompok eksperimen diberikan olahraga futsal yang diintegrasikan program life skills dan pada kelompok kontrol, olahraga futsal diberikan tanpa mengintegrasikan program life skills. Kendellen et al., (2017) memberikan empat langkah dalam menerapkan integrasi program life skills yaitu (a) fokus pada satu keterampilan hidup per pelajaran, (b) memperkenalkan keterampilan hidup pada awal pelajaran, (c) menerapkan strategi untuk mengajarkan kecakapan hidup sepanjang pelajaran, dan (d) menanyai kecakapan hidup pada akhir pelajaran.

Pada penelitian ini penulis menggunakan instrumen kuesioner life skills yang disusun oleh peneliti berdasarkan teori yang dikemukakan oleh (Bean et al., 2015). 
Jurnal Kejaora: Jurnal Kesehatan Jasmani dan Olah Raga

ISSN: 2541-5042 (Online)

ISSN: 2503-2976 (Print)

Volume 6 Nomor 2, Edisi November 2021

Instrumen kuesioner tersebut berisi 8 keterampilan hidup utama yang terdiri intrapersonal (e.g., focus, perseverance, goal setting, emotional regulation) or interpersonal (e.g., sportspersonship, honesty, teamwork, respect). Kuesioner terdiri dari 43 item pernyataan, dengan skala pengukuran berupa skala likert dengan rentang skala yang digunakan adalah rentang skala 5 poin yaitu dari skor 1 Sangat tidak setuju (STS) hingga 4 Sangat setuju (SS). Sebelum menggunakan instrumen tersebut peneliti melakukan pengujian validitas dan reliabilitas dengan menggunakan software IBM SPSS versi 25 dengan hasil uji validitas menggunakan nilai $r$ hitung dibandingkan dengan $r$ tabel, hasilnya $r$ hitung $>r$ tabel (0.2335). Demikian pula dengan hasil uji reliabilitas menggunakan nilai Alphacronbach's hasilnya $a=0,875$ dengan keputusan reliabel.

Data yang diperoleh dianalisis menggunakan uji-t, dengan bantuan SPSS versi 25 dengan taraf signifikasi $\alpha=0,05$.

\section{HASIL DAN PEMBAHASAN HASIL \\ 1. Uji normalitas}

Persyaratan pengujian analisis data yang pertama adalah menguji normalitas. Uji normalitas yang digunakan dalam penelitian ini adalah uji one Kolmogorov Smirnovz melalui IBM SPSS 25 dengan ketentuan apabila nilai signifikansi kurang dari 0,05 (Sig. $<0,05$ ) maka data berdistribusi tidak normal, sedangkan apabila nilai signifikansi lebih dari 0,05 (Sig. > 0,05) maka data berdistribusi normal. Hasil perhitungan uji normalitas data hasil life skills pada kelompok kelompok eksperimen (siswa yang mengikuti kegiatan ekstrakurikuler olahraga futsal yang diberikan program integrasi life skills) dan kelompok kontrol (siswa yang mengikuti kegiatan ekstrakurikuler olahraga futsal tanpa diberikan program integrasi life skills) dapat dilihat pada tabel 2 .

Tabel 2. Hasil Uji Normalitas Data Kelompok Eksperimen dan Kelompok Kontrol

$$
\text { K-S } \quad \begin{aligned}
& \text { Asymp. Sig. } \\
& \text { tailed })
\end{aligned}
$$

\begin{tabular}{llll}
\hline Pretest kelompok eksperimen & 0,177 & 0,200 & Data Normal \\
\hline $\begin{array}{l}\text { Posttest kelompok } \\
\text { eksperimen }\end{array}$ & 0,111 & 0,200 & Data Normal \\
\hline Pretest kelompok kontrol & 0,116 & 0,200 & Data Normal \\
\hline Posttest kelompok kontrol & 0,170 & 0,200 & Data Normal \\
\hline
\end{tabular}

Dari hasil output diatas dapat dipaparkan hasil sebagai berikut: 1) Tabel uji normalitas di atas menunjukkan untuk data hasil life skills pada pretest kelompok eksperimen diketahui bahwa nilai $\mathrm{KS}=0,177$ dan Signifikansi (Sig.) $=0,200>0,05$ maka Ho diterima, dengan demikian distribusi data dinyatakan normal; 2) Untuk data posttest kelompok eksperimen dengan nilai $\mathrm{KS}=$ 0,111 dan Signifikansi (Sig.) $=0,200>0,05$ maka Ho diterima, dengan demikian distribusi data dinyatakan normal; 3) untuk hasil perhitungan uji normalitas data hasil life skills pada pretest kelompok kontrol dari tabel di atas diketahui bahwa nilai $\mathrm{KS}=0,116$ dan Signifikansi (Sig.) $=0,200>0,05$ maka $\mathrm{Ho}$ diterima, dengan demikian distribusi data dinyatakan normal; 4) Untuk data posttest kelompok kontrol dengan nilai $K S=0,170$ dan Signifikansi (Sig.) $=0,200>0,05$ maka $\mathrm{Ho}$ diterima, dengan demikian distribusi data dinyatakan normal.

\section{Homogenitas}

Langkah berikutnya untuk persyaratan pengujian statistik adalah uji homogenitas. Statistik yang digunakan untuk menguji homogenitas adalah uji statistik One Way Anova melalui IBM SPSS 25 dengan ketentuan apabila (Sig.) $>0,05$ maka data homogen, sedangkan bila (Sig.) $<0,05$ data tidak homogen. Hasil perhitungan uji homogenitas data hasil life skills pretest dan 
Jurnal Kejaora: Jurnal Kesehatan Jasmani dan Olah Raga

ISSN: 2541-5042 (Online)

ISSN: 2503-2976 (Print)

Volume 6 Nomor 2, Edisi November 2021

posttest pada kelompok eksperimen dan

kelompok kontrol dapat dilihat pada tabel 3 .

Tabel 3. Hasil Uji Homogenitas Data Kelompok Eksperimen dan Kelompok Kontrol

\begin{tabular}{llll}
\hline & Leven Statistic & Sig. (2-tailed) & Keterangan \\
\hline $\begin{array}{l}\text { Pretest kelompok eksperimen } \\
\text { dan kontrol }\end{array}$ & 0,014 & 0,906 & Data homogen \\
\hline $\begin{array}{l}\text { Posttest kelompok } \\
\text { eksperimen dan kontrol }\end{array}$ & 0,082 & 0,777 & Data homogen \\
\hline
\end{tabular}

Dari tabel di atas perhitungan uji homogenitas pada pretest kelompok ekperimen dan kontrol diketahui bahwa nilai leven statistic $=0,014$ dan signifikansi (Sig.) $=$ $0,906>0,05$ maka Ho diterima, dengan demikian distribusi data dinyatakan homogen. Kemudian hasil perhitungan uji homogenitas pada posttest kelompok eksperimen dan kontrol dari tabel di atas diketahui bahwa nilai leven statistic $=0,082$ dan Signifikansi (Sig.) $=0,777>0,05$ maka
Ho diterima, dengan demikian distribusi data dinyatakan homogen.

\section{Pengujian hipotesis}

Statistik yang digunakan untuk menguji hipotesis adalah uji statistik paired samples test melalui IBM SPSS 25. Berikut adalah data hasil pengujian paired sample test, dapat dilihat pada tabel 3 .

Tabel 4. Uji Paired Sample Test Pada Kelompok Eksperimen

\begin{tabular}{llcll}
\hline & T & Sig. (2-tailed) & Keputusan & Kesimpulan \\
\hline Kelompok eksperimen & 7,897 & 0,000 & Ho Ditolak & Pengaruh signifikan \\
\hline
\end{tabular}

Dasar pengujian untuk uji pengaruh data adalah sebagai berikut:

Hipotesis:

a) $\mathrm{H}_{0}=$ Tidak terdapat pengaruh signifikan ekstrakurikuler (siswa yang mengikuti kegiatan ekstrakurikuler olahraga futsal yang diintegrasikan dengan komponen life skills) terhadap life skills siswa.

b) $\mathrm{H}_{1}=$ Terdapat pengaruh signifikan ekstrakurikuler (siswa yang mengikuti kegiatan ekstrakurikuler olahraga futsal tanpa integrasi komponen life skills) terhadap life skills siswa.

Kriteria Keputusan:

1. Nilai Signifikansi atau nilai probabilitas $>0,05$, Ho diterima dan Hi ditolak
2. Nilai Signifikansi atau nilai probabilitas $<0,05$, Ho ditolak dan $\mathrm{Hi}$ diterima

Keputusan:

Berdasarkan output data diperoleh nilai Sig.(2-tailed) sebesar 0,000 $<0,05$, maka sesuai dasar pengambilan keputusan Paired Samples Test, maka dapat disimpukan $\mathrm{Ho}$ ditolak $\mathrm{Hi}$ diterima, yang artinya bahwa terdapat pengaruh signifikan ekstrakurikuler (siswa yang mengikuti kegiatan ekstrakurikuler olahraga futsal yang diintegrasikan dengan komponen life skills) terhadap life skills siswa.

Hasil perhitungan uji hipotesis menggunakan Uji Paired Sample Test data pada kelompok kontrol dapat dilihat pada tabel 5. 
Jurnal Kejaora: Jurnal Kesehatan Jasmani dan Olah Raga

ISSN: 2541-5042 (Online)

ISSN: 2503-2976 (Print)

Volume 6 Nomor 2, Edisi November 2021

Tabel 5. Uji Paired Sample Test Pada Kelompok Kontrol

$\begin{array}{llll}T & \text { Sig. (2-tailed) } & \text { Keputusan } & \text { Kesimpulan } \\ 0,000 & 1,000 & \text { Ho Diterima } & \begin{array}{l}\text { Tidak } \\ \text { berpengaruh }\end{array}\end{array}$

Dasar pengujian untuk uji pengaruh data adalah sebagai berikut:

Hipotesis:

c) $\mathrm{H}_{0}=$ Tidak terdapat Pengaruh signifikan ekstrakurikuler (siswa yang mengikuti kegiatan ekstrakurikuler olahraga futsal yang diintegrasikan dengan komponen life skills) terhadap life skills siswa

d) $\mathrm{H}_{1}=$ Terdapat Pengaruh signifikan ekstrakurikuler (siswa yang mengikuti kegiatan ekstrakurikuler olahraga futsal tanpa integrasi komponen life skills) terhadap life skills siswa

Kriteria Keputusan:

3. Nilai Signifikansi atau nilai probabilitas $>0,05$, Ho diterima dan Hi ditolak

4. Nilai Signifikansi atau nilai probabilitas $<0,05$, Ho ditolak dan $\mathrm{Hi}$ diterma
Keputusan:

Berdasarkan output data diperoleh nilai Sig.(2-tailed) sebesar $1,000>0,05$, maka sesuai dasar pengambilan keputusan Paired Samples Test, maka dapat disimpukan $\mathrm{Ho}$ diterima $\mathrm{Hi}$ ditolak, yang artinya bahwa tidak terdapat pengaruh signifikan ekstrakurikuler (siswa yang mengikuti kegiatan ekstrakurikuler olahraga futsal tanpa integrasi komponen life skills) terhadap life skills siswa.

Dalam penelitian ini, untuk menguji perbandingan atau perbedaan dilakukan dengan menggunakan uji independent samples test melalui SPSS 25. Adapun hasil perhitungan uji hipotesis menggunakan Independent Samples Test pada kelompok eksperimen dan kelompok kontrol dapat dilihat pada tabel 6 .

Tabel 6. Uji Beda Gain Skor Kelompok Eksperimen dan Kelompok Kontrol

\begin{tabular}{llll}
$T$ & Sig. (2-tailed) & Keputusan & Kesimpulan \\
\hline 6,516 & 0,000 & Ho Diterima & Terdapat perbedaan pengaruh
\end{tabular}

Hipotesis yang diajukan:

a) $\mathrm{H}_{0}=$ Tidak terdapat perbedaan pengaruh hasil perkembangan life skills pada kelompok eksperimen dan kelompok kontrol.

b) $\mathrm{H}_{1}=$ Terdapat perbedaan pengaruh hasil perkembangan life skills pada pada kelompok eksperimen dan kelompok kontrol.

Kriteria Keputusan:

1. Nilai Signifikansi atau nilai probabilitas $>0,05$, Ho diterima dan Hi ditolak

2. Nilai Signifikansi atau nilai probabilitas $<0,05$, Ho ditolak dan $\mathrm{Hi}$ diterima

Berdasarkan output diatas diperoleh nilai Sig.(2-tailed) sebesar 0,000 <0,05 maka sesuai dasar pengambilan keputusan dalam Uji Independent Sample T-Test, maka disimpulkan Ho ditolak dan Hi diterima artinya bahwa terdapat perbedaan pengaruh perkembangan hasil life skills pada pada kelompok eksperimen dan kelompok kontrol.

\section{PEMBAHASAN}

Kegiatan ekstrakurikuler olahraga merupakan kegiatan jasmani yang diselenggarakan di sekolah dengan tujuan memberikan perkembangan kognitif, emosional, sosial, psikologis dan psikomotorik individu (YıImaz \& Güven, 2018) 
Jurnal Kejaora: Jurnal Kesehatan Jasmani dan Olah Raga

ISSN: 2541-5042 (Online)

ISSN: 2503-2976 (Print)

Volume 6 Nomor 2, Edisi November 2021

sekaligus memberikan keterampilan hidup (life skills) guna mempersiapkan individu untuk siap menghadapi tuntutan dan tantangan kehidupan sehari-hari (Durhan, 2021). Melalui ekstrakurikuler yang secara langsung terintegrasikan dengan life skills, siswa akan lebih memahami dan mengimplementasikan life skills dalam kehidupan sehari-harinya. Pemahaman terhadap nilai-nilai yang tersimpan dalam long term memory dapat menanamkan nilainilai yang baik itu sepanjang hayatnya. Hal ini sesuai dengan pendapat Gould \& Carson, (2008) bahwa konteks olahraga harus sengaja disusun secara sengaja untuk mengajarkan keterampilan hidup dan mendorong hasil perkembangan life skills dari pemuda. Collins et al., (2009); Gould et al., (2007) yang menyarankan agar pelatih dapat memahami pentingnya menggunakan olahraga sebagai alat untuk mengajarkan keterampilan hidup siswa.

Dalam penelitian ini dilakukan pretest dan posttest pada kelompok eksperimen maupun kelompok kontrol. Tujuannya untuk mengetahui seberapa besar pengaruh life skills pada kelompok eksperimen untuk kemudian dibandingkan dengan kelompok kontrol. Selama dilakukan treatment pada kelompok eksperimen, sintak yang diberikan ditekankan kepada 1) fokus pada satu keterampilan hidup per pelajaran b) keterampilan hidup yang akan dicapai, diperkenalkan pada awal pembelajaran c) merancang dan memiliih strategi yang tepat dalam mencapai tujuan untuk mengajarkan kecakapan hidup d) melakukan feedback dan penguatan terkait pembelajaran pada akhir pembelajaran, hal tersebut tentunya sesuai dengan yang diungkapkan oleh (Kendellen et al., 2017). Melalui tahap pelatihan dan pengajar yang terstruktur ini, diharapkan kemampuan life skills siswa akan mengalami peningkatan. Adapun data hasil penelitian melalui hasil pretest dan posttest adalah sebagai berikut:

\begin{tabular}{|c|c|c|c|c|}
\hline Kel & Jenis Life Skills & Pretest (\%) & Posttest (\%) & $\begin{array}{l}\text { Selisih } \\
\text { (\%) }\end{array}$ \\
\hline \multirow[t]{8}{*}{ Kontrol } & Focus & 10,37 & 10,98 & 0,61 \\
\hline & Perseverance & 10,09 & 10,53 & 0,44 \\
\hline & Goal setting & 11,32 & 11,92 & 0,6 \\
\hline & Emotional regulation & 8,73 & 9,92 & 1,19 \\
\hline & Sportpersonship & 10,04 & 11,01 & 0,97 \\
\hline & Honestly & 10,11 & 10,83 & 0,72 \\
\hline & Teamwork & 12,93 & 12,93 & 0 \\
\hline & Respect & 10,54 & 12,01 & 1,47 \\
\hline \multirow[t]{8}{*}{ Ekperimen } & Focus & 11,99 & 13,43 & 1,44 \\
\hline & Perseverance & 10,35 & 10,87 & 0,52 \\
\hline & Goal setting & 10,77 & 13,42 & 2,65 \\
\hline & Emotional regulation & 8,02 & 10,93 & 2,91 \\
\hline & Sportpersonship & 9,94 & 11,04 & 1,1 \\
\hline & Honestly & 10,21 & 10,93 & 0,72 \\
\hline & Teamwork & 12,65 & 12,84 & 0,19 \\
\hline & Respect & 10,23 & 11,42 & 1,19 \\
\hline
\end{tabular}

Dari hasil penelitian, diketahui bahwa pada kelompok kontrol terdapat peningkatan life skills dengan rincian: focus dengan selisih sebesar $0,61 \%$, perseverance $0,44 \%$, goal setting $0,6 \%$, sportpersonship 0,97\%, honestly $0,72 \%$, teamwork $0 \%$ dan respect
$1,47 \%$. Sedangkan pada kelompok eksperimen, terdapat selisih pretest dan posttest dengan rincian: focus dengan selisih sebesar $1,19 \%$, perseverance $0,52 \%$, goal setting $1,44 \%$, sportpersonship 1,1\%, honestly $0,72 \%$, teamwork $0,19 \%$ dan respect 
Jurnal Kejaora: Jurnal Kesehatan Jasmani dan Olah Raga

ISSN: 2541-5042 (Online)

ISSN: 2503-2976 (Print)

Volume 6 Nomor 2, Edisi November 2021

2,65\%. Dari data tersebut, diketahui bahwa pada kelompok kontrol maupun kelompok eksperimen memiliki kontibusi terhadap perkembangan life skills siswa. Namun meskipun demikian, terlihat bahwa life skills pada siswa mengalami peningkatan kemampuan secara signifikan saat diberikan treatment berupa program latihan ekstrakurikuler futsal yang diintegrasikan dengan program life skills pada kelompok eksperimen dibandingkan dengan program latihan ekstrakurikuler futsal yang tidak diintegrasikan dengan program life skills.

Pada kelompok eksperimen, diketahui bahwa peningkatan terbesar life skills terdapat pada kemampuan emotional regulation dengan peningkatan sebesar $2,91 \%$, goal setting sebesar $2,65 \%$ serta focus sebesar $1,44 \%$. Hal tersebut menunjukkan bahwa ketiga jenis life skills ini saling keterkaitan satu sama lain. Sejalan dengan hal tersebut, fakta dilapangan menunjukkan bahwa kemampuan siswa dalam mengelola dan mengatur emosi sangat terlihat ketika mereka sedang bermain di lapangan. Hasil observasi menunjukkan bahwa siswa yang telah diberikan treatment mulai mampu mengatur emosinya saat bertanding dengan lawannya. Nyatanya kemampuan ini juga sangat penting dimiliki oleh siswa khususnya saat menghadapi kompetensi. Dengan kemampuan emotional regulation yang baik, maka siswa yang sedang bertanding tidak akan mudah terpancing emosi yang akan mengaburkan focus dan tujuannya saat bertanding. Kemampuan emotional regulation siswa yang sangat baik secara tidak langsung dapat meningkatkan focus siswa sehingga tercapai goal setting yang diinginkan saat bertanding.

Bean \& Forneris, (2016) berpendapat bahwa mengajarkan life skills yang terintegrasikan tentunya akan membantu menjembatani kesenjangan antara keyakinan bahwa pengembangan dan transfer kecakapan hidup terjadi secara implisit dari sekadar partisipasi dalam olahraga dan membantu untuk mengenali nilai dengan sengaja mengintegrasikan pengembangan dan transfer keterampilan. Hal tersebut juga sejalan dengan penelitian Gilman, (2001) yang menemukan bahwa partisipasi dalam kegiatan ekstrakurikuler yang terintegrasi dengan life skills dikaitkan dengan kepuasan hidup yang lebih tinggi di antara remaja. (Larson, 2000) bahwa keterampilan hidup dapat dikembangkan melalui kegiatan ekstrakurikuler salah satunya adalah olahraga.

\section{KESIMPULAN}

Ekstrakurikuler futsal yang diintegrasikan program life skills dapat memberikan pengaruh yang lebih signifikan daripada ekstrakurikuler futsal tanpa integrasi program life skills terhadap peningkatan life skills siswa. Life skills merupakan hal penting yang perlu diajarkan kepada siswa sebagai upaya meningkatkan kualitas sumber daya manusia. Upaya pengembangan life skills di sekolah dapat dilakukan melalui berbagai cara, termasuk melalui kegiatan ekstrakurikuler. Hasil penelitian yang dilakukan menunjukkan bahwa ekstrakurikuler futsal yang diintegrasikan dengan life skills dapat memberikan dampak positif terhadap perkembangan kualitas kemampuan dan kepribadian siswa. Melalui program ekstrakurikuler futsal yang diitegrasikan dengan life skills, kemajuan perkembangan keterampilan siswa akan berjalan beriringan dengan semakin baiknya life skills siswa tersebut sehingga dapat menjadi bekal untuk siswa dalam menghadapi persaingan global yang kompetitif. Untuk memaksimalkan perkembangan siswa, baik dalam bermain futsal maupun dalam life skills maka diperlukan pelatihan futsal yang diintegrasikan dengan life skills secara kontinyu dan berkelanjutan.

\section{UCAPAN TERIMA KASIH}

Terlaksananya penelitian ini, tentunya tidak terlepas dari dukungan berbagai pihak. Melalui tulisan ini, penulis mengucapkan terima kasih yang sebesar-besarnya kepada seluruh pihak yang telah mendukung terlaksananya penelitian, terkhusus KEMENDIKBUDRISTEK, Sekolah Tinggi Keguruan dan IImu Pendidikan (STKIP) Pasundan, serta SMKN 9 Garut yang berperan besar terhadap berlangsungnya 
Jurnal Kejaora: Jurnal Kesehatan Jasmani dan Olah Raga

ISSN: 2541-5042 (Online)

ISSN: 2503-2976 (Print)

Volume 6 Nomor 2, Edisi November 2021

penelitian sampai dengan penelitian ini selesai.

\section{DAFTAR PUSTAKA}

Bean, C., \& Forneris, T. (2016). Is Life Skill Development a By-Product of Sport Participation? Perceptions of Youth Sport Coaches. Journal of Applied Sport Psychology, 29(2), 234-250. https://doi.org/10.1080/10413200.2016 .1231723

Bean, C., Kendellen, K., \& Forneris, T. (2015). Moving Beyond the Gym: Exploring Life Skill Transfer Within a Female Physical Activity-Based Life Skills Program. Journal of Applied Sport Psychology, 28(3), 274-290. https://doi.org/10.1080/10413200.2015 .1124155

Budiman, Rusmana, R., \& Wargadinata, L. U. (2020). Outdoor Education Of Emphathy Student. Jp.Jok (Jurnal Pendidikan Jasmani, Olahraga Dan Kesehatan), 4(1), 117-127. https://doi.org/10.33503/jp.jok.v4i1.873

Camiré, M., \& Trudel, P. (2013). Using High School Football to Promote Life Skills and Student Engagement: Perspectives from Canadian Coaches and Students. World Journal of Education, 3(3), 40-51. https://doi.org/10.5430/wje.v3n3p40

Carreres-Ponsoda, F., Carbonell, A. E., Cortell-Tormo, J. M., Fuster-Lloret, V., \& Andreu-Cabrera, E. (2012). The relationship between out-of-school sport participation and positive youth development. Journal of Human Sport and Exercise, 7(3), 671-683. https://doi.org/10.4100/jhse.2012.73.0 7

Collins, K. E., Gould, D., \& Chung, Y. (2009). Coaching Life Skills through Football: Philosophical Beliefs of Outstanding High School Football Coaches. Journal of Coaching Science. International Journal of Coaching Science, 3, 29-54.

Danish, S., Forneris, T., Hodge, K., \& Heke, I. (2004). Enhancing youth development through sport. World Leisure Journal, 46(3), 38-49. https://doi.org/10.1080/04419057.2004

.9674365

Durhan, T. A. (2021). the Relationship Between the Effect of Sports on Life Skills of Secondary School. International Journal of Eurasian Education and Culture, 6(12), 332-377. https://doi.org/10.35826/ijoecc.357

Esen, G. (2010). İlköğretim okulları 2. kademe öğrencilerinin beden eğitimi dersine ve ders dışı spor etkinliklerine yönelik tutumlarında beden eğitimi ögretmenlerinin rolü. Marmara Üniversitesi, Sağlık Bilimleri Enstitüsü, Yüksek Lisans Tezi.

Fraenkel, J., Norman, W., \& Helen, H. (2012). How to design and evaluate research in education. Eighth edition. Mc Graw hill.

Fraser-thomas, J. L., Côté, J., Deakin, J., \& Co, Â. J. (2007). Youth sport programs : an avenue to foster positive youth development Youth sport programs : an avenue to foster positive youth development " te. Physical Education and Sport Pedagogy, April 2012, 3741.

https://doi.org/10.1080/174089804200 0334890

Fredricks, J. A., \& Eccles, J. S. (2006). Is extracurricular participation associated with beneficial outcomes? Concurrent and longitudinal relations. Developmental Psychology, 42(4), 698-713. https://doi.org/10.1037/00121649.42 .4 .698

Gilman, R. (2001). The relationship between life satisfaction, social interest, and frequency of extracurricular activities among adolescent students. Journal of Youth and Adolescence, 30(6), 749767.

https://doi.org/10.1023/A:10122857297 01

Gould, D., \& Carson, S. (2008). Life skills development through sport: current status and future directions. International Review of Sport and Exercise Psychology, 1(1), 58-78. https://doi.org/10.1080/175098407018 34573

Gould, D., Collins, K., Lauer, L., \& Chung, Y. (2007). Coaching life skills through football: A study of award winning high 
Jurnal Kejaora: Jurnal Kesehatan Jasmani dan Olah Raga

ISSN: 2541-5042 (Online)

ISSN: 2503-2976 (Print)

Volume 6 Nomor 2, Edisi November 2021

school coaches. Journal of Applied Sport Psychology, 19(1), 16-37. https://doi.org/10.1080/104132006011 13786

Harrison, P., \& Narayan, G. (2006). Research Papers Research Papers. Acta Crystallographica Section B, 356(3), 867-876.

Holt, N. L., Tink, L. N., Mandigo, J. L., Fox, K. R., Mandigo, L., \& Fox, R. (2015). Do youth learn life skills through their involvement in high school sport? A case study. Canadian Journal of Education, 31(2), 281-304.

Johnston, J., Harwood, C., Minniti, A. M., Harwood, C., \& Douglas, J. (2012). Positive Youth Development in Swimming: Clarification and Consensus of Key Psychosocial Assets. January 2013, 37-41. https://doi.org/10.1080/10413200.2012 .747571

Jones, M. I., \& Lavallee, D. (2009). Exploring perceived life skills development and participation in sport. Qualitative Research in Sport and Exercise, 1(1), 36-50.

https://doi.org/10.1080/193984408025 67931

Kendellen, K., Camiré, M., Bean, C. N., Forneris, T., \& Thompson, J. (2017). Integrating life skills into Golf Canada's youth programs: Insights into a successful research to practice partnership. Journal of Sport Psychology in Action, 8(1), 34-46. https://doi.org/10.1080/21520704.2016 .1205699

Larson, R. W. (2000). Culture and Social Support. American Psychologist, 55(1), 170-183. https://doi.org/10.1037/0003066X.55.1.170

Rohmanasari, R., Ma'mun, A., \& Muhtar, T. (2019). Dampak Kegiatan Ekstrakurikuler terhadap Perkembangan Life Skills Siswa Sekolah Menengah Atas. Jurnal Penelitian Pendidikan, 18(3), 371-382. https://doi.org/10.17509/jpp.v18i3.1500 9

Yılmaz, A., \& Güven, Ö. (2018). Examination of the psychometric properties of the 